\title{
A prospective study to compare the effectiveness of adjunctive rectal misoprostol or oxytocin titration in the prevention of primary post-partum haemorrhage in at risk patients
}

\author{
Rafat Muhammad, Aliyu Isah, Teddy Agida, Godwin Akaba
}

University of Abuja Teaching Hospital, Gwagwalada, Abuja, Nigeria, Obstetrics and Gynaecology

\begin{abstract}
Background: Adjunctive uterotonic in patients at risk of primary post-partum haemorrhage may reduce its incidence. Objective: To compare the effectiveness and safety of adjunctive rectal misoprostol with adjunctive intravenous oxytocin for the prevention of primary post-partum haemorrhage in at risk patients.

Materials and methods: A total of 122 patients with risk factors for uterine atony were allocated to receive either $600 \mu \mathrm{g}$ of rectal misoprostol $(\mathrm{n}=61)$ or $20 \mathrm{IU}$ of oxytocin infusion $(\mathrm{n}=61)$ after routine management of third stage of labour. Post-partum blood loss was measured using differential delivery towel and pad weighing.

Results: There was similarity in the estimated post-partum blood loss, with no significant difference in the mean post-partum hematocrit levels between the adjunctive rectal misoprostol group and oxytocin infusion group $(\mathrm{P}=0.712)$. There was no difference in the need for additional intervention of uterotonics between the two groups. There were however, higher incidences of shivering and pyrexia among those that received misoprostol compared with the oxytocin group.

Conclusion: Rectal misoprostol is as effective and safe as oxytocin when used as an adjunctive uterotonic in preventing primary post-partum haemorrhage in patients with risk factors for uterine atony after active management of third stage of labour.
\end{abstract}

Keywords: Adjunctive rectal misoprostol, primary post-partum haemorrhage, patients.

DOI: https://dx.doi.org/10.4314/ahs.v19i1.25

Cite as: Muhammad R, Isah A, Agida T, Akaba G. A prospective study to compare the effectiveness of adjunctive rectal misoprostol or oxytocin titration in the prevention of primary post-partum haemorrhage in at risk patients. Afri Health Sci. 2019;19(1). $1517-1524$. bttps:/ / dx.doi.org/10.4314/abs.v19i1.25

\section{Introduction}

Post-partum haemorrhage $(\mathrm{PPH})$ is an important cause of maternal morbidity and mortality especially in the developing countries. ${ }^{1}$ Post-partum Haemorrhage (PPH) is commonly defined as a blood loss of $500 \mathrm{ml}$ or more after vaginal delivery ${ }^{2}$ or blood loss in excess of $1000 \mathrm{ml}$ after caesarean delivery. ${ }^{3}$ For clinical purposes however, any blood loss enough to cause hemodynamic instability

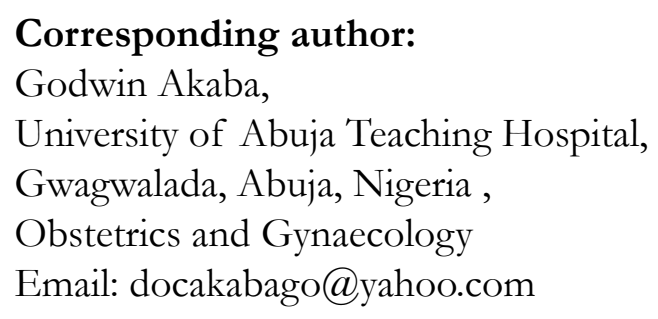

is also termed post-partum haemorrhage. ${ }^{4}$ It is said to be "primary" when it occurs within 24 hours of delivery and "secondary" when the bleeding occurs after 24 hours of delivery. ${ }^{2}$

It is responsible for $25 \%$ of maternal deaths worldwide. ${ }^{5}$ The incidence of post-partum haemorrhage $(\mathrm{PPH})$, is higher in low-resource countries than the rest of the world. ${ }^{5}$ In Nigeria in a study done in North-Central Zone, post-partum haemorrhage was responsible for $34.6 \%$ of maternal mortality. ${ }^{6}$

The causes of mortality are multi-factorial, and prevention requires a multi-disciplinary response. ${ }^{7}$ The most common cause of $\mathrm{PPH}$ is uterine atony which accounts for $70 \%$ of cases leading to severe postnatal anaemia and haemorrhagic shock requiring transfusions and surgical interventions. ${ }^{8}$

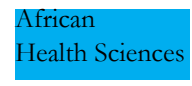

(C) 2019 Muhammad et al. Licensee African Health Sciences. This is an Open Access article distributed under the terms of the Creative commons Attribution License (https://creativecommons.org/licenses/BY/4.0), which permits unrestricted use, distribution, and reproduction in any medium, provided the original work is properly cited. 
Oxytocin is a cyclic nona-peptide that stimulates the upper segment myometrium to contract rhythmically, constricts spiral arteries and decreases blood flow through the uterus. ${ }^{9}$ Thus, it is an effective first-line treatment for post-partum haemorrhage. ${ }^{10}$ The effectiveness of oxytocin titration for the prevention of $\mathrm{PPH}$ in at risk women is not in doubt. However, the lack of power supply for appropriate storage of oxytocin and the absence of non-parenteral routes of administration of the drug are important factors limiting its optimal use in rural communities in Nigeria. These challenges herald the need for alternatives.

However, whether misoprostol which is also an active uterotonic agent that allows the uterus to contract within a few minutes ${ }^{11,12,13}$ with added advantages of being relatively stable at room temperature, inexpensive, rapidly absorbed into the circulation after rectal administration, and not requiring much skill is as effective and safe as oxytocin titration in preventing PPH in at risk women after active management of third stage of labour (AMTSL) is unclear.

The objective of this study therefore, was to compare the safety and efficacy of adjunctive rectal misoprostol and intravenous oxytocin titration for prevention of post-partum haemorrhage in at risk patients, after routine active management of the third stage of labour. For this study adjunctive rectal misoprostol was defined as insertion of $600 \mathrm{ug}$ of misoprostol per rectum after routine management of third stage of labour.

The study hypothesized that there was no difference in effectiveness and safety between rectal misoprostol and oxytocin titration in the prevention of post-partum haemorrhage in at risk patients. It is expected that the findings from this research would contribute towards answering the research question: Is rectal misoprostol as safe and effective as intravenous oxytocin titration for the prevention of primary post-partum haemorrhage in at risk patients after routine AMTSL?

\section{Materials and method}

This study was conducted at the University of Abuja Teaching Hospital to compare the effectiveness and safety of adjunctive rectal misoprostol (cases) with intravenous oxytocin titration (control) for prevention of postpartum haemorrhage in at risk patients after routine active management of the third stage of labour.

The hospital is a 350 bed Federal tertiary health facility that provides health care services to the inhabitants of Abuja and neighbouring states. Abuja's total population is estimated to be about 6 million in 2017. The obstetric unit has a total of 38 beds, while the labour ward has 12 delivery beds. About 2,500 deliveries are conducted annually.

The study population was comprised of consecutive women in labour who were at risk of PPH. Awareness about the study was created at the Antenatal clinic and written informed consent was obtained from each eligible patient following delivery of the placenta when routine active management of third stage would have been effected. The Research Ethics Committee of the University of Abuja Teaching Hospital approved the conduct of the study.

\section{Inclusion criteria}

These included all parturients with predisposing factors to uterine atony who had given consent to be part of the study. The risk factors for uterine atony included: grand-multiparity, multiple gestation, precipitate labour, chorioamnionitis, polyhydramnios, fetal macrosomia, previous caesarean section, coagulation defect, previous $\mathrm{PPH}$, induced/augmented labour and other medical conditions like hypertension and diabetes

\section{Exclusion criteria}

This was done after recruitment but before interventions. These included patients with hematocrit less than 30\% and those with any contraindications to prostaglandin use. Other exclusion criteria were those that presented in second and third stages of labour as well as those who had episiotomy, perineal lacerations and cervical laceration.

\section{Sample size determination}

The primary outcome measure for this study was post-partum blood loss of equal to or more than $500 \mathrm{ml}$. The sample size of 122 women for both arms of the study was calculated using the formula for calculation of sample size for case control studies with dichotomous primary outcome $e^{14}$ on the following assumptions: 
- Sample size adjustment for dropout of $10 \%$.

-Oxytocin titration would prevent PPH in $93.2 \%$ based on report from a previous study ${ }^{15}$

-The study was designed to detect a difference of $20 \%$ (effect size) before it can be considered to be clinically significant.

-Significance level of 5\% for the hypothesis test and a power of 80 per cent (or 0.8).

\section{Methods of allocation into study groups/interven- tions}

A total of one hundred and twenty-two women with risk factors for uterine atony were recruited. All the procedures were carried out by the researchers and, the research assistants who had been trained on measurement of blood loss.

Blood samples were taken for pre-delivery hematocrit estimation, and grouping and cross-matching of blood.

Allocation into two study groups was achieved using computer-generated list by a statistician who was not part of the investigators. A slip of paper allocating the patient into either of the two study groups was placed in sequentially numbered, opaque, sealed envelopes indicating their medication. One group of patients received $600 \mu \mathrm{g}$ of misoprostol rectally (Group 1) while the other group received $20 \mathrm{IU}$ of oxytocin (Rotexmedica) in $500 \mathrm{ml}$ of Normal saline water infusion at a rate of 30 drops per minute to last 4 hours after routine management of the third stage of labour (Group2). The latter is the standard of care in the study setting for the prevention of $\mathrm{PPH}$ among high risk women after active management of third stage of labour.

Immediately after delivery of the baby, administration of intramuscular 10IU of oxytocin, clamping and division of the cord, a new delivery towel (Nightingale) weighing $0.1 \mathrm{~kg}$ was placed beneath the perineum before the delivery of placenta in order to eliminate the liquor. After the delivery of placenta by controlled cord traction, uterine massage was done and thereafter those in the misoprostol group had $600 \mu \mathrm{g}$ of misoprostol administered rectally while in the second group, oxytocin titration was commenced.
The patients were monitored in the labour ward for 2 hours. All the soaked drapes and pads were weighed and the old weight was subtracted from the new weight. A hundred gram increase in weight was considered to be equivalent to $100 \mathrm{ml}$ of blood loss (assuming specific gravity of blood equivalent to $1 \mathrm{gm} / \mathrm{ml})^{16}$.

The initial measurement was after delivery of the placenta. Subsequently, patients had hourly measurement of the delivery towel/pad twice before being transferred to the maternity ward, where monitoring was continued for twenty-four hours. Each pad removed by the patient within the first 24 hours of delivery while still in the maternity ward was also weighed and the difference in weight calculated as already stated. The weighing was carried out by any member of the team of researchers. Post-delivery blood sample was taken 24 hours after delivery to determine the hematocrit before discharge. Data was prospectively collected using a structured proforma.

\section{Primary and secondary outcome measures}

The primary outcome measure was development of postpartum haemorrhage while secondary outcome measures included; significant change in pre and post delivery haematocrit, severe post partum haemorrhage, the need for additional uterotonics, blood transfusion and medication side effects.

\section{Data analysis}

Data was analysed using statistical package social sciences (SPSS Version 16). Categorical variables were analysed using Chi2 - test, Mann Whitney and Fishers exact test were used for comparison of means where appropriate. A P-value of less than 0.05 was accepted as indicating statistical significance.

\section{Results}

The result of the study is as shown in the consort flow diagram (Figure 1). A total of 122 women with risk factors for PPH were allocated to receive either, adjunctive rectal misoprostol(cases), $(n=61)$ or oxytocin titration, (control) ( $\mathrm{n}=61)$ after active management of the third stage of labour. However, it was only 110 patients (misoprostol, $n=56$ ) and (oxytocin titration $n=54$ ) that were eventually analysed, following exclusion of 12 women that either had cervical laceration $(n=2)$ or perineal lacerations $(n=10)$. None of the patients opted out after giving consent and recruitment. 


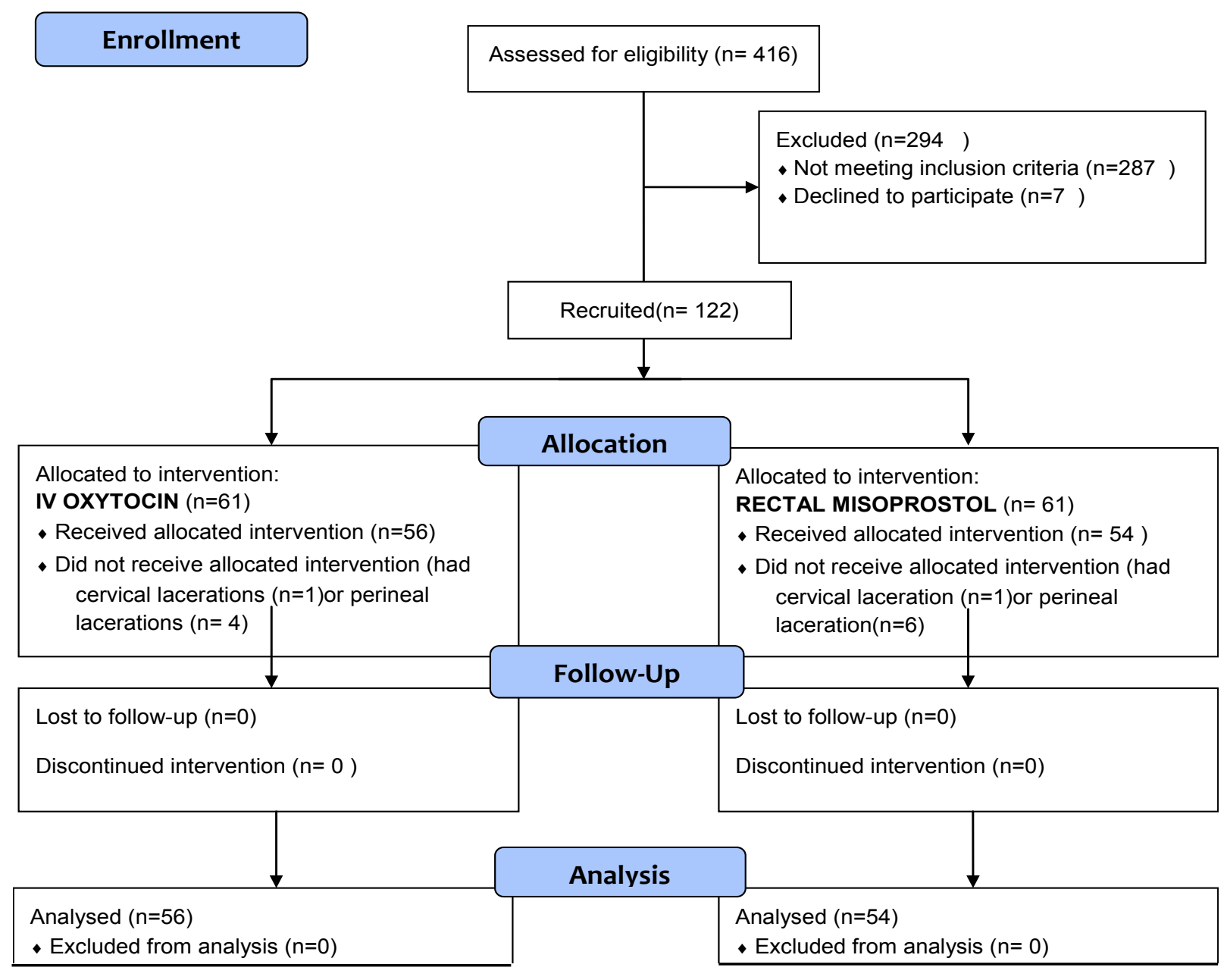

Figure 1: CONSORT Flow Diagram

The baseline characteristics of the participants were similar for both groups as shown in table 1 . The results with respect to the selected risk factors for $\mathrm{PPH}$ for the two groups are also shown in table 1 . No statistically significant difference was obtained between the groups for any of the risk factors.

When the mean estimated blood loss measurements were compared, there was a relatively higher blood loss among the misoprostol group $(457.6 \pm 377.5 \mathrm{ml})$, than recorded in the oxytocin group $(440.4 \pm 301.8 \mathrm{ml})$. However, this difference was not statistically significant $(P=0.712)$. There was also a marginal higher incidence of $\mathrm{PPH}$ in the misoprostol group (19.6\%) compared to $18.5 \%$ in the oxytocin group. This difference just like in the former was also not statistically significant $(\mathrm{P}=0.902)$. 
Table 1: Baseline characteristics of the study participants

Parameter

$\operatorname{Age}($ years $)$ mean $\pm \mathrm{SD}^{\mathrm{a}}$

Booked $^{\mathrm{b}}$

Unbooked $^{\mathrm{b}}$

Nullipara ${ }^{b}$

Multipara ${ }^{\mathrm{b}}$

Gestation in weeks

Mean + SD $^{\mathrm{a}}$

Twin gestation

Induction of labour

Oxytocin Augmentation

Magnesium Sulphate

Fetal macrosomia

Antepartum haemorrhage

Previous caesarean

Fibroid in pregnancy

Chorioamnionitis

Mann-Whitney ${ }^{\mathrm{a}}$, Fishers exact test ${ }^{\mathrm{b}}$
Rectal Misoprostol

600ug $\mathrm{N}=56(\%)$

$28.3 \pm 4.4$

44(78.6)

$12(21.4)$

12(21.4)

44(78.6)

$39.9+1.9$

$1(1.8)$

17(30.4)

23(41.1)

$4(7.1)$

$1(1.8)$

2(3.6)

2(3.6)

$1(1.8)$

1(1.8)

Chi-square
Oxytocin 20IU

$500 \mathrm{ml}$

Normal/Saline

$\mathrm{N}=\mathbf{5 4}(\%)$

$28.1 \pm 3.4$

0.618

43(79.4)

0.539

11(20.4)

0.912

6(11.1)

0.309

48(88.9)

0.674

$38.8+1.5$

0.627

2(3.7)

0.618

$12(22.2)$

0.533

23(42.6)

0.918

4(7.4)

0.960

2(3.7)

0.980

2(3.7)

0.972

$5(9.3)$

0.439

1(1.9)

0.980

2(3.7)

0.618
The mean pre-delivery haematocrit was $31.9 \%$ ( Group 1) versus $31.8 \%$ (Group 2) while the mean post-delivery haematocrit was $30.5 \%$ (Group1) versus $30.8 \%$ (Group 2).

There were no significant differences either in the predelivery, post -delivery and changes in haematocrit percentages in the two groups. $(\mathrm{P}=0.995,0.676$, and 0.861 respectively).

We observed no statistically significant difference $(\mathrm{P}=$ $0.789)$ in the proportion of women with post-partum blood loss of $>1000 \mathrm{mls}$ between the misoprostol ( $\mathrm{n}=5$; $8.9 \%)$ and oxytocin $(n=4 ; 7.4 \%)$ groups (Table 2$)$. 
Table 2: Primary and secondary outcomes measures indicative of blood loss.

\begin{tabular}{|c|c|c|c|}
\hline Parameters & $\begin{array}{l}\text { Rectal } \\
\text { Misoprostol 600ug } \\
\text { N=56(\%) }\end{array}$ & $\begin{array}{l}\text { Oxytocin } 20 I U \\
\text { in 500ml } \\
\text { Normal/Saline } \\
\text { N=54(\%) }\end{array}$ & p-value \\
\hline Average EBL in $\mathrm{ml}$ & $457.6+377.5$ & $440.4+301.8$ & 0.712 \\
\hline $\mathrm{EBL}>500 \mathrm{ml}<1000 \mathrm{ml}^{\mathrm{c}}$ & $11(19.6)$ & $10(18.5)$ & 0.902 \\
\hline $\mathrm{EBL} \geq 1000 \mathrm{ml}^{\mathrm{c}}$ & $5(8.9)$ & $4(7.4)$ & 0.789 \\
\hline Pre-delivery Haematocrit ${ }^{\mathrm{a}}$ & $31.9 \pm 2.14$ & $31.8+1.9$ & 0.995 \\
\hline Post-delivery Haematocrit ${ }^{\mathrm{a}}$ & $30.5+2.40$ & $30.8+2.7$ & 0.676 \\
\hline Change in Haematocrit ${ }^{\mathrm{a}}$ & $1.6 \pm 1.90$ & $1.4 \pm 1.6$ & 0.086 \\
\hline Additional Uterotonic ${ }^{c}$ & $7(12.5)$ & $6(11.1)$ & 0.841 \\
\hline Blood Transfusion & $1(1.7)$ & - & \\
\hline Mann-Whitney $^{\mathrm{a}}$, Chi-square & & & \\
\hline
\end{tabular}

Comparable proportion of women $7(12.5 \%)$ in the misoprostol group versus $6(11.1 \%)$ in the oxytocin group required additional uterotonics. This marginal variation was not statistically significant. Only one patient in the misoprostol group had blood transfusion.

Secondary outcome measures did not show any significant difference specifically in relation to severe $\mathrm{PPH}$ (EBL $>1000 \mathrm{mls}$ ), additional uterotonics and blood transfusion.
Considering the patients with regards to adverse effects of the drugs, none of the patients in the two groups had nausea and vomiting. Of particular interest was the incidence of shivering which was higher $(7.1 \%)$ in the misoprostol group as against $(1.9 \%)$ in the oxytocin group. This difference was not statistically significant $(\mathrm{P}=0.37)$. Pyrexia greater than $37.5^{\circ} \mathrm{C}$ was more commonly observed among the misoprostol group, 25(45\%) compared to $5(9.2 \%)$ in the oxytocin group and the difference was found to be statistically significant $(\mathrm{P}=0.002)$. This is shown in table 3 .

\section{Table 3: Medication side effects}

$\begin{array}{ll}\text { Parameter }^{\mathrm{b}} & \begin{array}{l}\text { Rectal Misoprostol } \\ 600 \mathrm{ug} \\ \mathrm{N}=56(\%)\end{array}\end{array}$

Shivering

Temperature $>37.5^{\circ} \mathrm{C}$
$4(7.1)$

25(45)

\section{Oxytocin 20IU in $500 \mathrm{ml}$, Normal/Saline $\mathrm{N}=\mathbf{5 4}(\%)$}

$1(1.9)$

$5(9.2)$ p- value

0.366

0.002

Fishers exact test ${ }^{\mathrm{b}}$ 


\section{Discussion}

In low to middle income countries (LMICs) like other parts of the world, post-partum haemorrhage is regarded as one of the major causes of maternal morbidity and mortality. ${ }^{1}$ Active management of the third stage of labour with the parenteral administration of oxytocin as the most important step has been widely recommended for the prevention of $\mathrm{PPH} .{ }^{2}$ Studies on adjunctive treatment for at risk patients after AMTSL for prevention of $\mathrm{PPH}$ is crucial towards further reduction of PPH especially in LMICs.

The incidence of $\mathrm{PPH}$ in the misoprostol group was $19.6 \%$ which was similar to $18.5 \%$ observed in the oxytocin group and comparable with $22.2 \%$ Versus $20.9 \%$ respectively reported by Badejoko et al in South West Nigeria. ${ }^{17}$ This study demonstrated that there was no significant difference in the incidence of PPH in both groups and is also comparable to findings from previous quotedstudy. ${ }^{17}$

The higher incidences of PPH recorded in our study as well as in the earlier study conducted in Nigeria utilizing adjunctive uterotonics after AMTSL ${ }^{17}$ affirms the magnitude of PPH in Nigeria to be high. This finding suggests that the incidence of PPH may have been much higher in this obstetric population in the absence of adjunctive uterotonics since all the patients had AMTSL.

There was no difference in the mean haematocrit values observed. The mean pre- delivery haematocrit, post -delivery haematocit, and change in haematocrit were not statistically significantly different between the two groups. These findings on the post haematocrit values have therefore corroborated the results of the estimated blood loss to be true since the post haematocrit value should be a reflection of the estimated blood loss. Blood losses $<500 \mathrm{ml}$ usually do not result in significant drop in haematocrit. ${ }^{18}$

The limited use of blood transfusion which was done for only one patient in the misoprostol group was not unexpected as the mean post delivery haematocrit for both groups were above the reference range for anaemia which suggests that majority of the patients were stable and that the adjunctive treatments may have helped in preventing further blood loss amongst patients who developed PPH. The absence of nausea and vomiting in both groups may have emanated from the point of view that both drugs were not administered using the oral route that possesses those familiar side effects. This finding may make either of the drugs more appealing to the patients when there is need for the use of either agent.

The recorded higher incidence of shivering and pyrexia in this study among the misoprostol group is in keeping with previous studies on the use of misoprostol for prevention and treatment of PPH. ${ }^{17,19,20,21,22}$ Shivering and pyrexia from misoprostol are expected due to prostaglandin E effects on central thermoregulation centre. ${ }^{16}$

This study has shown no statistical significant difference, in efficiency and safety between rectal misoprostol and oxytocin infusion in the prevention of $\mathrm{PPH}$, after routine management of third stage of labour in patients at risk of PPH. However, rectal misoprostol was associated with fever which was self-limited.

This efficacy and safety demonstrated by misoprostol, as an alternative to oxytocin infusion in preventing PPH in at risk women may be a welcome research finding. It will allow its guided use in developing countries and low resource settings where oxytocin infusion can be cumbersome especially in the rural communities where there is dart of human resources. This finding has a tendency to support the wide spread marketing of misoprostol in rural health care clinics/hospitals in developing countries like ours, due to its ease of administration by even nonskilled personnel towards reduction in the incidence of PPH.

The study is however limited by the fact that neither the patients nor investigators were blinded as regards the interventions. The small sample size may limit its generalizabilty thereby signaling the need for larger studies to investigate this important subject towards reducing maternal morbidity and mortality from PPH in developing countries.

\section{Conflict of interest}

The authors do not have any conflict of interest to declare. 


\section{References}

1. Khan KS, Wojdyla D, Say L, Gülmezoglu AM, Van Look PF. WHO analysis of causes of maternal death: A systematic review. Lancet. 2006; 367 (9516): 1066-74.

2. World Health Organization. WHO recommendations for the prevention and treatment of post-partum haemorrhage. 2012.Available at:http://apps.who.int/iris/bitst ream/10665/75411/1/9789241548502_eng.pdf (accessed 16/12/2016)

3. El-Rafey S, Rodeck C. Post-partum haemorrhage: definitions, medical and surgical management. A time for change. Br Med Bull. 2003; 67: 205-17 PubMed.

4. Leduce D,Senikas V,Lalonde A.B,Ballerman C,Biringer A,Delaney M, et al. Active management of the third stage of labour: Prevention and treatment of post-partum hemorrhage. J Obstet Can. 2009;31(10):980-93. PubMed.

5. Ujah IA, Aisien OA, Mutihir JT, Vanderjagt DJ, Glew RH, Uguru VE. Maternal mortality among adolescent women in Jos, North Central, Nigeria. J Obstet Gynaecol. 2005; 25:3-6. PubMed.

6. Ujah IA, Aisien OA, Mutihir JT,Vanderjagt DJ, Glew RH, Uguru VE. Factors contributing to maternal mortality in North-Central Nigeria. Afr J Reprod Health. 2006; 9:27-40.

7. Mobeen N, Durochev J, Zuberi NF,Jahan N,Blum J, Wasim S, et al. Administration of Misoprostol by trained traditional Birth Attendants to prevent Post-Partum Hemorrhage in Pakistan: A randomised -Placebo- Controlled Trial. BJOG 2010; 118:353-61. PubMed.

8. Westhoff G, Cotter AM,Tosola JE .Prophylactic oxytocin for the third stage of labour to prevent post-partum haemorrahge. Cochrane database Syst Rev. 2013; 30 :( 10):CD001808. doi: 10.1002/14651858.CD001808.pub2. 9. Blanks AM, Thornton S. The role of oxytocin in parturition. BJOG. 2003; 110(20): 46-51.

10. Soriano D,Dulitzki M,Schiff E,Barkai G,Mashiach S,Seidman DS. A prospective cohort study of oxytocin plus ergometrine compared with oxytocin alone for prevention of post-partum haemorrhage. BrJ Obstet Gynaecol. 1996; 103(11):1068-73.

11. Kararli T, Catalano T, Needham TE. Mechanism of misoprostol stabilization in hydroxypropyl methylcellulose. Adv Exp Med Biol.1991; 302: 275-89. PubMed.
12. Gaud HT, Connors KA. Misoprostol dehydration kinetics in aqueous solution in the presence of hydroxypropylmethylcellulose . J Pharm Sci. 1992; 81: 145-8. PubMed. 13. Ayyad I, Omar AA. Prevention of post-partum hemorrhage by rectal misoprostal. A randomized controlled trial. Middle East Journal of Family Medicine, 2004; 5: 1-6. 14. Wingo PA, Higins JE, Rubin GL. et al. Sample size and power. In:Epidemiologic Approach to Reproductive Health, WHO Geneva, Switzerland. 1994; 151-200.

15. Rogers J,Wood J, McCandlish R, Ayers S, Truesdale A, Elbourne D. Active versus expectant management of third stage of labour: the Hinchingbrooke randomised controlled trial. Lancet. 1998;7:351(9104):693-9. PubMed. 16. Afolabi EO, Kuti O, Orji EO, Ogunniyi SO. Oral misoprostol versus intramuscular oxytocin in the active management of the third stage of labour. Singapore Med J. 2010:51(3):207-11. PubMed.

17. Badejoko OO, Ijarotimi AO, Awowole IO, Loto OM, Badejoko BO, Olaiya DS.et al.Adjunctive rectal misoprostol versus oxytocin infusion for prevention of post-partum hemorrhage in women at risk: A randomized controlled trial. J Obstet Gynaecol Res. 2012; 38(11):1294-301. 18. Kodkang BS, Derman RJ. Pitfalls in assessing blood loss and decision to transfer. Textbook of Postpartum Haemorrhage, Sapiens Publishing 2006; 4: 39-40. PubMed.

19. Nasr A, Shahin A, Elsamman AM,Zakherah MS,Shaabon OM. Rectal misoprostol versus intravenous oxytocinfor prevention of post-partum hemorrhage Int J Gynecol Obstet. 2009; 105(3):244-247.

20. Firouzbakht M, Kiapour A, Omidyar S. Prevention of post-partum haemorrhage by rectal misoprostol:A randomised clinical trial. J Nat Sc Biol Med. 2013; 4:134137 PubMed.

21. Tunçalp Ö, Hofmeyr GJ, Gülmezoglu AM. Prostaglandins for preventing post-partum haemorrhage. Cochrane Database Syst Rev. 2012; 15 :( 8): CD000494. Epub. 2012 Aug 15.

22. Widmer M, Blum J, Hofmeyr GJ, Carroli G, Abdel-AleemH, Lumbiganon P, ThiNhu Ngoc N et al. Misoprostol as an adjunct to standard uterotonics for treatment of post-partum haemorrhage: A multicentre, double-blind randomised trial. Lancet. 2010; 375(9728): 1808-1813. 